\title{
Negative Regulation of Microtubule Depolymerization
}

National Cancer Institute

\section{Source}

National Cancer Institute. Negative Regulation of Microtubule Depolymerization. NCI

Thesaurus. Code C41588.

Any microtubule process that stops, prevents or reduces the frequency, rate or extent of microtubule depolymerization. 